\title{
AN ANALYSIS OF WEEKLY OUT-OF-HOME DISCRETIONARY ACTIVITY PARTICIPATION AND TIME-USE BEHAVIOR
}

Erika Spissu

The University of Texas at Austin

Department of Civil, Architectural \& Environmental Engineering

1 University Station, C1761, Austin, TX 78712

Tel: (512) 232-6599; Fax: (512) 475-8744; Email: espissu@unica.it

Abdul Rawoof Pinjari

University of South Florida

Department of Civil \& Environmental Engineering

4202 E. Fowler Avenue, ENC 2503

Tampa, FL 33620

Tel: (813) 974-9671; Fax: (813) 974-2957; Email: apinjari@eng.usf.edu

Chandra R. Bhat*

The University of Texas at Austin

Department of Civil, Architectural \& Environmental Engineering

1 University Station, C1761, Austin, TX 78712

Tel: (512) 471-4535; Fax: (512) 475-8744; Email: bhat@mail.utexas.edu

Ram M. Pendyala

Arizona State University

Department of Civil and Environmental Engineering

Room ECG252, Tempe, AZ 85287-5306

Tel: (480) 727-9164; Fax: (480) 965-0557; Email: ram.pendyala@asu.edu

Kay W. Axhausen

ETH Zurich

IVT ETH - Honggerberg, HIL F 32.3

Wolfgang Pauli Strasse 15, 8093, Zurich, Switzerland

Tel: 41 (1) 63339 43; Fax: +41 (1) 63310 57; Email: axhausen@ivt.baug.ethz.ch

*corresponding author 


\begin{abstract}
Activity-travel behavior research has hitherto focused on the modeling and understanding of daily time use and activity patterns and resulting travel demand. In this particular paper, an analysis and modeling of weekly activity-travel behavior is presented using a unique multi-week activity-travel behavior data set collected in and around Zurich, Switzerland. The paper focuses on six categories of discretionary activity participation to understand the determinants of, and the inter-personal and intra-personal variability in, weekly activity engagement at a detailed level. A panel version of the Mixed Multiple Discrete Continuous Extreme Value model (MMDCEV) that explicitly accounts for the panel (or repeated-observations) nature of the multi-week activity-travel behavior data set is developed and estimated on the data set. The model also controls for individual-level unobserved factors that lead to correlations in activity engagement preferences across different activity types. To our knowledge, this is the first formulation and application of a panel MMDCEV structure in the econometric literature. The analysis suggests the high prevalence of intra-personal variability in discretionary activity engagement over a multi-week period along with inter-personal variability that is typically considered in activitytravel modeling. In addition, the panel MMDCEV model helped identify the observed socioeconomic factors and unobserved individual specific factors that contribute to variability in multi-week discretionary activity participation.
\end{abstract}

Keywords: activity-travel behavior, multiweek analysis, inter-personal variability, intra-personal variability, discrete-continuous model, panel data, unobserved factors 


\section{INTRODUCTION}

\subsection{Background}

The focus of activity-travel behavior analysis has traditionally been on the understanding and modeling of daily time use and activity patterns. This tradition has largely been maintained for three reasons. First, transportation planning efforts are generally aimed at modeling and quantifying travel demand on a daily basis (or peak hour/period basis) and therefore most travel surveys collect information about activities and travel for just one day from survey respondents. Second, there is concern about respondent fatigue that may result from collecting detailed activity-travel information over multiple days. Third, from a methodological standpoint, the availability of analytic tools required to estimate econometric models of multi-period activity time-use behavior has been limited.

The use of one-day data, however, limits the ability to understand the temporal variations and rhythms in activity-travel behavior (Goodwin, 1981; Kitamura, 1988). Specifically, single day analyses implicitly assume uniformity in activity decisions from one day to the next. While this assumption is questionable even for work participations of an employed individual (because of, for example, increased temporal flexibility and more part-time workers), it is certainly not reasonable for discretionary activities such as leisure, sports, and even shopping or personal business. For such activities, it is possible that individuals consider longer time frames such as a week as the temporal unit for deciding the extent and frequency of participation (e.g., I will shop once this week during the weekend; I will go to the gym on Tuesday and Thursday; etc.). In other words, for discretionary activity participation, it is quite likely that simple one-day data sets (or even multi-day data sets) may not capture the range of choices that people are exercising with respect to their activity engagement. In fact, several earlier studies (Hanson and Hanson, 1980; Hanson and Huff, 1988; Kitamura, 1988; Muthyalagari et al., 2001; Pas, 1987; Pas and Sundar, 1995; Pendyala and Pas, 1997) have shown substantial day-to-day variations in discretionary activity participations, and some earlier studies (see, for example, Bhat et al., 2004, Bhat et al., 2005, and Habib et al., 2008) have provided empirical evidence that discretionary activity participations may be characterized as being on a weekly (or perhaps longer time scale) rhythm. Thus, modeling discretionary activity participation and time allocation on a weekly basis may provide a better foundation for understanding trade-offs in activity-travel engagement and scheduling of activities, which in turn should provide an improved framework for modeling daily 
activity-travel patterns. On the other hand, modeling daily activity-travel patterns using a single survey day (as is done in practice today) has some very real limitations from a behavioral and policy standpoint. From a behavioral standpoint, single day analyses do not recognize that individuals who have quite dissimilar patterns on the survey day may in fact be similar in their patterns over a longer period of time. Such a case would arise if, for example, two individuals have the same behavioral pattern over a week, except that their cyclic patterns are staggered. Similarly, single day analyses do not recognize that individuals who appear similar in their patterns on the survey day may have very different patterns over longer periods of time. The net result is that models based on a single day of survey may reflect arbitrary statistical correlations, rather than capturing underlying behavioral relationships between activity-travel patterns and individual/built environment characteristics. From a policy standpoint, because models based on a single day do not provide information about the distribution of participation over time (that is, the frequency of exposure over periods longer than a day) of different sociodemographic and travel segments, they may be unsuitable for the analysis of transportation policy actions, as discussed by Jones and Clark (1988) and Hirsh et al. (1986). For example, when examining the impact of congestion pricing policies on trips for discretionary activities, it is important to know whether an individual participates in such activities everyday or whether the individual has a weekly shopping rhythm. Besides, many policies are likely to result in re-scheduling of activities/trips over multiple days. For instance, a compressed work week policy may result in some activities being put off from the weekdays to the weekend days, as demonstrated by Bhat and Misra (1999).

The motivation for this paper stems from the discussion above. Specifically, we focus on formulating and estimating a model of discretionary activity participation and time-use within the larger context of a weekly activity generation model system. Just as there have been several earlier efforts to model activity participation and time-use as a component of single-day activitytravel pattern microsimulation systems (see Bhat et al., 2004, Pendyala et al., 2005), we envision our effort here as an important component of a multi-day activity-travel pattern microsimulation system. In fact, as sketched out by Doherty et al. (2002), daily activity-travel patterns can be viewed as the end-result of a weekly activity-travel scheduling process in which the individual takes as input a weekly agenda of activity episodes, constructs a basic weekly skeleton based on the agenda, and updates the weekly skeleton in a dynamic fashion reflecting continued addition 
and revisions over time. ${ }^{1}$ The research of Doherty and colleagues (Doherty et al. 2002, Mohammadian and Doherty, 2005; 2006) focuses on the weekly activity-travel scheduling process, given the weekly activity agenda (the activity agenda generation process is not considered in their research). The current paper, on the other hand, contributes to the weekly agenda generation process, which can be conceptualized as comprising three sub-modules: (1) a weekly model of work participation, regular work hours, and sleep duration (not modeled here, but relatively straightforward to consider as a function of household/individual demographic and residential location attributes), (2) a weekly discretionary activity participation and time-use model, but including time-use in non-discretionary, non-routine work, and non-sleep activities (focus of the current paper), and (3) a weekly activity episode generation module (beyond the scope of the current paper). The third sub-module considers participation and time-use in workrelated activities, sleep activities, as well as in discretionary and "other” (non-discretionary, nonroutine work, and non-sleep) activities, to output a weekly activity episode agenda (an activity episode agenda is a list of activity types in which an individual wishes to participate, along with desired contextual attributes such as number of episodes per week, mean duration per episode, possible locations for participation, accompaniment for participation, travel mode, and time-ofday). This third sub-module can take the form of a series of sequenced econometric or rule-based models, similar to the case of translating activity participation and time-use decisions for a single day into a daily agenda of activity episodes (the details of this sub-module are however left for future research).

\subsection{The Current Research in the Context of Earlier Studies}

As indicated earlier, there have been several earlier studies focusing on activity-travel participation dimensions over multiple days. These studies may be grouped into three categories. The first category of studies has focused on examining day-to-day variability in one or more dimensions of activity-travel behavior. Almost all earlier multi-day studies belong to this category. Examples include Hanson and Hanson (1980), Pas (1983) and Koppelman and Pas (1984), Hanson and Huff (1986; 1988), Huff and Hanson (1986; 1990), Kitamura (1988), Muthyalagari et al., (2001), Pas (1987), Kunert (1994), Pas and Sundar (1995), Pendyala and Pas

\footnotetext{
${ }^{1}$ Doherty et al.'s study suggests that activity-travel behavior may be guided by an underlying activity scheduling process that is associated with multiple time horizons that range from a week (or, perhaps, more than that) to within a day.
} 
(1997), and Schlich et al., (2004). These studies show, in general, substantial day-to-day variability in individual activity-travel patterns and question the ability of travel demand models based on a single day of data to produce good forecasts and accurately assess policy actions. For instance, Pas (1987) found, in his five-day analysis of an activity data set from Reading, England, that about 50 percent (63 percent) of the total variability in daily number of total out-of-home activity episodes (leisure activity episodes) may be attributed to within-individual day-to-day variability. Kunert, in his analysis of a one-week travel diary collected in Amsterdam and Amstelveen in 1976, found that the average intrapersonal variance is about $60 \%$ of the total variation in daily trip rates and concluded that "even for well-defined person groups, interpersonal variability in mobility behavior is large but has to be seen in relation to even greater intrapersonal variability”. The studies by Hanson and Huff indicated that even a period of a week may not be adequate to capture much of the distinct activity-travel behavioral patterns manifested over longer periods of time. The second category of studies has examined multi-day data to identify if there are distinct rhythms in shopping and discretionary activity participation. Examples include Bhat et al. (2004) and Bhat et al. (2005). These studies use hazard duration models to model the inter-episode durations (in days) for shopping and discretionary (social, recreation, and personal business) activity participations, and examine the hazard profiles for spikes (which indicate a high likelihood of termination of the inter-episode durations or, equivalently, of increased activity participation). The results indicate a distinct weekly rhythm in individuals' participation in social, recreation, and personal business activities. While there is a similar rhythm even for participation in shopping activities, it is not as pronounced as for the discretionary activity purposes. A third category of multi-day studies have been motivated from the need to accommodate unobserved heterogeneity across individuals in models of daily activity-travel behavior (unobserved heterogeneity refers to differences among individuals in their activity-travel choices because of unobserved individual-specific characteristics). Examples include Bhat (1999) and Bhat (2000). These studies indicate that relationships based on crosssectional data (rather than multi-day data) provide biased and inconsistent discrete choice behavioral parameters, and incorrect evaluations of policy scenarios (see Diggle et al., 1994 for an econometric explanation for why relationships based on cross-sectional data yield inconsistent parameters in non-linear models in the presence of unobserved individual heterogeneity; intuitively, differences between individuals because of intrinsic individual-specific habitual/trait 
factors get co-mingled with differences between individuals because of exogenous variables, corrupting non-linear model parameter estimates).

In addition to the studies above that have focused on daily activity-travel behavior (and its variation across days), there have been a few instances of studies of weekly activity-travel behavior. Pas (1988) examined the relationship between weekly activity-travel participation and daily activity-travel patterns, as well as the relationships between weekly activity-travel behavior and the hypothesized determinants of this behavior. He showed that weekly activity-travel patterns may be grouped into a small number of general pattern types while retaining much of the information in the original patterns; in other words, there are weekly rhythms of activitytravel engagement that can describe activity-travel engagement over a period of time. Kraan (1996) modeled total weekly time allocated by individuals to in-home, out-of-home, and travel for discretionary activities using data from a Dutch Time Budget Survey (“TijdsBestedingsOnderzoek”, TBO). In a recent study, Habib et al. (2008) examined time-use in several coarsely-defined activities, and found that model parameters did not change significantly when applied to each individual week of a 6-week activity data collected in Germany. Based on this, they concluded that a typical week captures rhythms in activity-travel behavior adequately. Beyond the field of transportation, Juster et al. (2004) analyzed weekly average time use for American children by age, gender, family type, and ICT (computer) availability and use. Newman (2002) used quasi-experimental data from Ecuador to understand the impacts of women's employment on household paid and unpaid labor allocation between men and women. They do this by collecting weekly time use data to better capture the occasional contribution to housework by men in Ecuador.

In this paper, we also adopt a weekly time unit of analysis to examine participation and time-use, with emphasis on discretionary activity participations. Unlike the many multi-day studies of daily activity-travel behaviour discussed earlier, the current study focuses on weekly activity-travel behaviour. However, unlike the weekly activity-travel behaviour studies discussed above that do not examine week-to-week variability, we expressly do so by using a 12-week activity diary data. Thus, this paper contributes to the literature by understanding and quantifying the weekly-level inter-individual variability and week-to-week intra-individual variability in discretionary activity engagement and time-use. To our knowledge, no previous study in the 
transportation field or other fields has attempted to quantify week-to-week variability. ${ }^{2}$ The reader will note that by using multiple weeks of data from the same individual, we are also able to control for unobserved individual heterogeneity. As in the case of multiday analysis, ignoring such heterogeneity when present (as is done if we consider a cross-sectional analysis using a single week of data from each individual, or ignore the dependency between multiple weeks of data from the same individual) will provide a poorer data fit and inconsistent behavioral parameters, as we illustrate later in the paper. In addition, the study also recognizes that weekly discretionary activity participation and time allocation is not a simple collection of isolated decisions on different discretionary activities. Rather, the decisions of activity engagement and time allocation in multiple types of discretionary activities tend to be joint in nature, with tradeoffs across different activity types. Another important feature of our analysis is that we define the discretionary activity types in a rather fine manner, with six types - social, meals, sports, cultural, leisure, and personal business (see detailed definitions in next section). ${ }^{3}$

From a methodological perspective, this paper formulates and presents a "panel” Mixed Multiple Discrete Continuous Extreme Value (panel MMDCEV) model that simultaneously accommodates correlations in activity engagement preferences across different weeks of the same individual, expressly considers the joint nature of activity participation decisions in multiple activity types (as opposed to focusing on a single activity type such as shopping), and recognizes individual-level unobserved correlations in preferences for different activity types. This is an important and non-trivial extension of the cross-sectional mixed MDCEV model that Bhat has developed and refined over the years (see Bhat, 2005 and Bhat, 2008). This is akin to the extension of the cross-sectional mixed multinomial logit (MMNL) model to the panel MMNL model, except that the MNL model is much simpler than the MDCEV model. The

2 Bhat et al. $(2004,2005)$ base their conclusion of weekly rhythms on a visual inspection of the hazard profile and confine attention to the participation decision without attention to time allocation, while Habib et al. (2008) base their conclusion of weekly rhythms in participation/time-use on the stability of model parameters estimated separately on each of six weeks of data. In both these studies, while there may be some suggestion of weekly periodicity of activity participation in relatively coarsely defined discretionary activities, there is no quantification whatsoever of the within-individual week-to-week variability and between-individual variability.

3 The use of this classification system is motivated by the differences in the activity-travel dimensions (participation rates, durations, time-of-day of participations, accompaniment arrangement, etc.) associated with episodes of each type. For instance, earlier time-use studies have provided evidence that participation rates in social and leisure (window shopping, making/listening music, etc.) activities tend to be higher than in other discretionary activities. Also, when participated in, episodes of these activities are participated for long durations. However, social activity episodes are mostly pursued with friends and family, while leisure activities are mostly pursued alone (see, for example, Kapur and Bhat, 2007). The basis for the other activity types is provided in the next section. 
estimation framework for the panel MMDCEV model is considerably more involved than for the cross-sectional MMDCEV model. To our knowledge, this is the first formulation and application of the panel MMDCEV model in the econometric literature. We also develop an innovative approach to assess the level of weekly-level inter-individual variability and week-to-week intraindividual variability in the latent baseline preferences for each activity type from the results of the panel MMDCEV model.

The rest of this paper is structured as follows. The next section discusses the data source and sample, as well as the discretionary activity type classification. Section 3 presents the panel MMDCEV model structure and the model estimation method. Section 4 provides a description of the sample, including an analysis of variance (ANOVA) to quantify the extent of intra-personal and inter-personal variation in discretionary activity-travel participation over a multi-week period. Section 5 presents the empirical results. The final section concludes the paper by highlighting key findings and identifying directions for future research.

\section{DATA}

The data set for this paper is derived from the Twelve Week Leisure Travel Survey designed and administered by the Institut für Verkehrsplanung und Transportsysteme, administered in the Zurich region. The data were collected from January $15^{\text {th }}$ to May $30^{\text {th }} 2002$ in 3 different waves; the first wave was administered on January 15, the second was administered three weeks later, and the last wave was administered six weeks later. Individuals in each wave reported their behavior for 12 consecutive weeks. The interviewees were selected from the telephone book based on place of residence (one third each in Zurich, Männedorf, and Opfikon) and household size (one third each in 1, 2, 2+ households).

The survey collected information on out-of-home discretionary activity episodes undertaken by 71 individuals (28 in Zurich, 20 in Opfikon, and 23 in Männedorf). The information collected on activity episodes included the activity type/purpose (coded into a 31category classification system), start and end times of activity participation, day of the year, with whom the episode was pursued, expenditure on activity, and the geographic location of activity participation (including the number of visits before the current episode). Travel episodes were characterized only by the mode used (to and from the destination). Furthermore, data on individual and household socio-demographics, individual employment-related characteristics, 
household auto ownership, fixed commitments, mobility information and tools, parking, social networks and accessibility measures were also obtained. Altogether, the respondents reported 5561 discretionary activities on 5936 days, which is about one discretionary activity per individual per day, consistent with other surveys on travel behavior. Additional details about the data and survey administration can be found in Stauffacher et al. (2005).

The 31 types of out-of-home $(\mathrm{OH})$ discretionary activity episodes were aggregated into six activity purposes in this study.

1. Social: Activities (club meeting, meeting relatives, honorary/unpaid help, church, etc.) that usually involve (or are performed with) other people and that are "social" in nature.

2. Meals: Eat out of home in restaurants, pub, etc. This is a separate activity because of its potential repetitive nature. Further, when the weekly time allocations are translated into weekly activity agenda attributes, it may help to have a separate meal activity category that is usually associated with specific times in the day.

3. Sports: Physically active sports (working out at the gym, jogging, all types of active sports). This activity has implications for public health, and tends to have quite different activity participation dimensions relative to other discretionary activities (see Bhat and Lockwood, 2004)

4. Cultural: Activities related to the arts and events/shows (also festivals, parties, etc.), including sports shows. Activities related to arts and sports events/shows are grouped together in this category because they are all spectator events. Also, all these activities are physically inactive in nature, compared to the physically active sport activities in the previous category. In addition, these events tend to have externally fixed timings and are likely to have more schedule constraints than physically active sport activities.

5. Leisure: Pastime or enjoyable activity; comprise all activities that do not necessarily require managing plans with other people and do not involve sports that are undertaken on a regular basis (e.g., going for a walk, window shopping, making/listening music, further education, excursions).

6. Personal Business: Personal business and maintenance activities reported by the respondents as performed at their own discretion in their leisure time (pick up/drop 
off, child care, car care, etc.). Work, work-related business, education/school, and shopping are included in personal business if individuals reported these activities as discretionary activities.

The total amount of weekly time spent in each of the 6 activity purposes was computed for the weekly MMDCEV analysis. Along with the time spent in each of the above mentioned $6 \mathrm{OH}$ discretionary activities, the time spent in 'other' activity purposes was computed by subtracting the weekly amount of time spent in $\mathrm{OH}$ discretionary activities, the weekly work hours and the weekly sleep duration (assumed to be 7 hours a day) from the total weekly time budget (60 × 24 $\times 7$ minutes). The final sample for analysis includes the weekly activity time allocation information for 12 weeks for each of the 71 individuals in the data (i.e., a total of 852 weekly time allocation observations).

\section{MODELING METHODOLOGY}

In this paper, a panel version of the mixed multiple discrete-continuous extreme value (MMDCEV) model is formulated to analyze weekly time-investment among the following seven activity purposes: (1) $\mathrm{OH}$ social, (2) $\mathrm{OH}$ meals, (3) $\mathrm{OH}$ sports, (4) $\mathrm{OH}$ cultural, (5) $\mathrm{OH}$ leisure, (6) $\mathrm{OH}$ personal business, and (7) Other. ${ }^{4}$

The model formulation accommodates heterogeneity (i.e., differences in behavior) across individuals due to both observed and unobserved individual attributes. In addition, the model formulation also considers individual-specific unobserved attributes that may make an individual more (or less) pre-disposed towards specific groups of activity types. The unobserved individual specific attributes may include attitudinal factors and life style preferences such as healthconsciousness, laid-back life style, active life style, and socially oriented nature. Consider for example, an individual who maintains a physically active life style and who is a sports enthusiast. This individual is likely to associate higher than average utility (in her/his observationally identical peer group) for $\mathrm{OH}$ sporting activities and $\mathrm{OH}$ sport shows (a subcategory in the cultural activity type). Similarly, an individual who is more socially oriented and more out-of-home oriented than the individuals in her/his observationally identical peer group is

\footnotetext{
4 The inclusion of the 'other' activity in the analysis enables the analyst to endogenously estimate the total timeinvestment in the first 6 types of $\mathrm{OH}$ discretionary activity purposes. In the presentation of the model structure later in this section, we will label this "other" activity purpose as the first alternative for presentation convenience.
} 
likely to associate higher utility for $\mathrm{OH}$ social and $\mathrm{OH}$ meal activities. The net result of such unobserved individual factors is an increase in the sensitivity towards the aforementioned groups of activities (the $\mathrm{OH}$ sports and $\mathrm{OH}$ cultural group, and the $\mathrm{OH}$ social and $\mathrm{OH}$ meal group, respectively). Econometrically speaking, there may be common unobserved factors that affect the utility of groups of activity types to generate correlations across the random utility terms (or error terms) of the alternatives in those groups.

It is important to note that the inter-alternative error term correlation structure just discussed operates at the individual-level, and contributes to individual-level unobserved heterogeneity. This error correlation does not operate at the choice occasion (i.e., individualweek) level. This warrants the use of a "panel" mixed multiple discrete-continuous extreme value (MMDCEV) model. In the following presentation of the panel MMDCEV model structure, the index $q(q=1,2, \ldots, Q)$ is used to denote individuals, $t\left(t=1,2, \ldots, T_{q}\right)$ for weekly choice occasion, and $k(k=1,2, \ldots, K)$ for activity purpose. Let $\boldsymbol{x}_{q t}=\left\{x_{q t 1}, x_{q t 2}, \ldots, x_{q t K}\right\}$ be the vector of time investments in week $t$ in 'other' activities $\left(x_{q 11}\right)$ and $\mathrm{OH}$ discretionary activities $\left(x_{q t 2}, x_{q t 3}, \ldots, x_{q t K}\right) . .^{5}$ Using these notational preliminaries, the structure of the weekly time-use model for panel (or repeated choice) data is discussed next.

Consider the following additive utility functional form: 6

$$
U_{q t}\left(\boldsymbol{x}_{q t}\right)=\psi_{q t 1} \ln x_{q t 1}+\sum_{k=2}^{K} \gamma_{k} \psi_{q t k} \ln \left(\frac{x_{q t k}}{\gamma_{k}}+1\right) \text {. }
$$

\footnotetext{
${ }^{5}$ All individuals in the sample participate for some non-zero amount of time in 'other' activities, and hence this alternative (which we will consider as the first alternative) constitutes the "outside alternative" that is always consumed (see Bhat, 2008 for details). The term "outside alternative" refers to an alternative that is "outside" the purview of the choice of whether to be consumed or not. The rest of the $(K-1)$ "inside" alternatives that are "inside" the purview of whether to be consumed or not correspond to the $\mathrm{OH}$ discretionary activities. Thus the first element of $\boldsymbol{x}_{q t}$ should always be positive, while the second through $K^{\text {th }}$ elements of $\boldsymbol{x}_{q t}$ can either be zero or some positive value. Whether or not a specific $x_{q t k}$ value $(k=2,3, \ldots, K)$ is zero constitutes the discrete choice component, while the magnitude of each non-zero $x_{q t k}$ value constitutes the continuous choice component. In this paper, the terms "time investments" and "time use" are used interchangeably to refer to these discrete-continuous $x_{q t k}$ values.

${ }^{6}$ Some other utility function forms were also considered, but the one specified here provided the best data fit while allowing for estimation of all the parameters without any identification problems. For conciseness, these alternative forms are not discussed. The reader is referred to Bhat (2008) for a detailed discussion of alternative utility forms. The reader will also note the implicit assumption in the formulation that there is utility gained from investing time in $\mathrm{OH}$ discretionary activities. This is a reasonable assumption since individuals have the choice not to participate in such activities. Also the reader will note that the inclusion of the IH and $\mathrm{OH}$ maintenance and $\mathrm{IH}$ discretionary activities as the "outside good" (the first alternative) allows the analyst to endogenously estimate the total amount of time invested in $\mathrm{OH}$ discretionary pursuits.
} 
In the above utility function, $U_{q t}\left(\boldsymbol{x}_{q t}\right)$ refers to the utility accrued to the individual due to time investment vector $\boldsymbol{x}_{q t}$ in week $t$. The term $\psi_{q t k}\left(\right.$ and $\left.\psi_{q t 1}\right)$ corresponds to the marginal random utility of one unit of time investment in alternative $k(k=1,2, \ldots, K)$ at the point of zero time investment for the alternative for the individual $q$ at choice occasion $t$ (as can be observed by computing $\left.\partial U_{q t}\left(\boldsymbol{x}_{q t}\right) /\left.\partial x_{q t k}\right|_{t_{q k}=0}\right)$. Thus, the $\psi_{q t k}$ terms $(k=1,2, \ldots, K)$ control the discrete choice participation decision in the inside alternatives $(k=2,3, \ldots, K)$ for individual $q$ at choice occasion $t$ (the specification in Equation (1) guarantees some amount of participation in the “outside” alternative 1 , as discussed in Bhat, 2008). The $\psi_{q t k}$ term will be referred to as individual $q$ 's baseline preference for alternative $k(k=1,2, \ldots, K)$ at choice occasion $t$. The term $\gamma_{k}\left(\gamma_{k}>0\right)$ is a translation parameter that serves to allow corner solutions (zero consumption) for the "inside" alternatives $k=2,3, \ldots, K .{ }^{7}$ Further, in combination with the logarithmic functional form, it also serves to allow differential satiation effects across these inside alternatives, with values of $\gamma_{k}$ closer to zero implying higher satiation (or lower time investment) for a given level of baseline preference (see Bhat, 2008 for details). There is no $\gamma_{1}$ term for the first alternative in Equation (1) because it is always consumed and precludes a corner solution (i.e., zero consumption) for the first alternative. However, satiation effects in the consumption of this first alternative are captured through the logarithmic functional form (so that marginal utility decreases with increasing time investment). To complete the model specification, the baseline parameter for alternative 1 is expressed as:

$$
\psi_{q t 1}=\exp \left(\varepsilon_{q t 1}\right)
$$

and that for other alternatives $(k=2,3, \ldots, K)$ as:

$$
\psi_{q t k}=\exp \left(\theta_{k}+\beta^{\prime} z_{q k}+\mu_{q}^{\prime} s_{k}+\eta_{q}^{\prime} w_{k}+\varepsilon_{q t k}\right) .
$$

In the baseline parameter expression for alternative 1 in Equation (2) (i.e., outside alternative), the term $\varepsilon_{q t 1}$ represents an idiosyncratic term assumed to be identically and independently standard type I extreme-value distributed across individuals and choice occasions, as well as independent of the terms in the baseline parameter expression for other alternatives. The terms in

\footnotetext{
7 The constraints that $\gamma_{k}>0(k=2,3, \ldots, K)$ are maintained through appropriate parameterizations (see Bhat, 2008). Also, the $\gamma$ parameters are subscripted only by activity purpose $k$ (unlike the $\psi$ parameters that are subscripted by $q$, $t$, and $k$ ) because specification tests in our empirical analysis did not show statistically significant variation in these parameters based on individual specific or time-specific observed/unobserved characteristics.
} 
the baseline parameter expression for the inside alternatives in Equation (3) $(k=2,3, \ldots, K)$ are as follows. The first term $\theta_{k}$ represents the "average” (across individuals) effect of unobserved variables on the baseline utility associated with alternative $k$. The second component $\beta^{\prime} z_{q k}$ captures heterogeneity across individuals due to observed individual specific attributes (i.e., observed inter-individual heterogeneity). In this component, $\beta$ is a vector of coefficients, and $z_{q k}$ is a vector of observed attributes specific to individual $q$ and introduced in an alternativespecific fashion (there are no observed attributes associated with either alternatives or choice occasions in the context of the current analysis). The third component $\mu_{q}^{\prime} s_{k}$ represents individual $q$ 's differential preference for the alternative $k$ compared to the "average" preference for the alternative $k$ across all her/his peer individuals. In this component, $s_{k}$ is a column vector of dimension $K$ with each row representing an alternative (the row corresponding to alternative $k$ takes a value of 1 and all other rows take a value of 0 ), and the vector $\mu_{q}$ (of dimension $K$ ) is specified to be a $K$-dimensional realization from a multivariate normally distributed random vector $\mu$, each of whose elements have a variance of $\sigma_{k}^{2}$. The elements of $\mu$ are assumed to be independent of each other, and the realization vector for any individual is independent of the realization vector of other individuals. The result is a variance of $\sigma_{k}^{2}$ across individuals (with no resulting covariance effects) in the utility of alternative $k$. Thus, the third component captures heterogeneity across individuals due to unobserved individual attributes that are not correlated across alternatives (i.e., unobserved pure variance inter-individual heterogeneity). The fourth component $\eta_{q}^{\prime} w_{k}$ constitutes the mechanism to generate individual level correlation across unobserved utility components of the alternatives. In this component, $w_{k}$ is specified to be a column vector of dimension $H$ with each row representing a group $h(h=1,2, \ldots, H)$ of alternatives sharing common individual-specific unobserved components (the row(s) corresponding to the group(s) of which $k$ is a member take(s) a value of one and other rows take a value of zero; i.e., $w_{h k}=1$ if $k$ belongs to group $h$ and 0 otherwise), and the vector $\eta_{q}$ (of dimension $H$ ) may be specified as a $H$-dimensional realization from a multivariate normally distributed random vector $\eta$, each of whose elements have a variance of $\omega_{h}^{2}$. The elements of $\eta$ are assumed to be independent of each other, and the realization vector for any individual is 
independent of the realization vector of other individuals. The result is a variance of $\sum_{h} w_{h k} \omega_{h}^{2}$

across individuals in the utility of alternative $k$ with an associated covariance between alternatives $k$ and $l$ of $\sum_{h} w_{h k} w_{h l} \omega_{h}^{2}$. Thus, this fourth component captures heterogeneity across individuals due to unobserved individual attributes that are correlated across alternatives (we will refer to the variance heterogeneity term $\sum_{h} w_{h k} \omega_{h}^{2}$ as the unobserved covariance-based interindividual heterogeneity). The fifth term $\varepsilon_{q t k}$ is an idiosyncratic choice-occasion specific term for individual $q$ and alternative $k$, assumed to be identically and independently standard type I extreme-value distributed across individuals, alternatives (activity purposes), and choice occasions. The variance of this standardized error term captures unobserved intra-individual heterogeneity (i.e., variation across choice occasions of individual $q$ ) in the baseline preference for alternative $k .^{8}$

The reader will note here that the $\mu_{q}$ and $\eta_{q}$ vectors, which are realizations of the $\mu$ and $\eta$ vectors for individual $q$, take the same value for all observations (or choice occasions) of a given individual. This generates correlations across the choice occasions of a given individual. Thus, individuals who may be predisposed to participate in $\mathrm{OH}$ social activity due to unobserved personality traits will show this predisposition across all her/his choice occasions.

\footnotetext{
8 Multiple discrete-continuous extreme value models (whether MDCEV or MMDCEV) require identification restrictions analogous to single discrete choice (i.e., multinomial logit, whether mixed or not) models, because the probability expression for the observed optimal time investments is completely characterized by the $(K-1)$ utility differences (Bhat, 2008). Thus, the MMDCEV model requires the usual location normalization of one of the alternative-specific constants/variables to zero (this is the reason for the absence of a $\theta_{1}$ term and a $\beta^{\prime} z_{1}$ term in Equation 1). Further, as with the current context, when there is no price variation across alternatives, the scale of the utility is normalized by standardizing the type I extreme-value distributed error terms $\varepsilon_{q t k}$. While one can, subject to some identification considerations, allow the choice-occasion specific error terms $\varepsilon_{q t k}$ to have different variances across alternatives, and allow choice-specific covariances across alternatives, we assume that these error terms are identically and independently distributed. Also, appropriate identification restrictions need to be imposed on the third and fourth components of the utility components in the main text above. These two components generate the individual-level variance-covariance matrix of the overall individual-level error terms affecting the logarithm of the alternative-specific baseline preferences. The identification conditions can be derived in a straightforward manner by examining the variance-covariance matrix of the implied error term differences in a manner similar to that for a cross-sectional model (see Bhat, 2008). In our empirical specification, we apply restrictions on the individual-level variance-covariance matrix that are more than sufficient for identification. We should also note here that we considered individual-level unobserved heterogeneity for the outside alternative (i.e., the first alternative), which can indeed be estimated in a panel setting subject to appropriate identification restrictions on the covariance terms. However, this term did not turn out to be statistically significantly different from zero, and so we did not introduce unobserved inter-individual heterogeneity terms in Equation (2) for the outside alternative.
} 
For given values of $\mu_{q}$ and $\eta_{q}$, the probability of the observed time investments (or, in view of the analyst, the optimal time investments) $\boldsymbol{x}_{q t}^{*}=\left\{x_{q t 1}^{*}, x_{q t 2}^{*}, \ldots, x_{q t K}^{*}\right\}$ of individual $q$ at choice occasion $t$ is given by (Bhat, 2008):

$$
P\left(x_{q t}^{*}\right) \mid\left(\eta_{q}, \mu_{q}\right)=\left[\prod_{i=1}^{M} c_{q t i}\right]\left[\sum_{i=1}^{M} \frac{1}{c_{q t i}}\right]\left[\frac{\prod_{i=1}^{M} e^{V_{q i}}}{\left(\sum_{k=1}^{K} e^{V_{q t k}}\right)^{M}}\right]\left(M_{q t}-1\right) \text { ! where }
$$

$M_{q t}=$ the number of alternatives chosen by individual $q$ at choice occasion $t$,

$c_{q t 1}=\left(\frac{1}{x_{q t 1}^{*}}\right)$, and $c_{q t i}=\left(\frac{1}{x_{q t i}^{*}+\gamma_{i}}\right)$ for $i=2,3, \ldots, M$,

$V_{q t 1}=-\ln x_{q t 1}^{*}$, and

$V_{q t k}=\theta_{k}+\beta^{\prime} z_{q k}+\mu_{q}^{\prime} s_{k}+\eta_{q}^{\prime} w_{k}-\ln \left(\frac{x_{q t k}^{*}}{\gamma_{k}}+1\right)(k=2,3, \ldots, K)$.

\subsection{Model Estimation}

The parameters to be estimated in the MMDCEV model include the $\theta_{k}$ and $\gamma_{k}$ scalars for each alternative $k$, the $\beta$ vector, and the $\sigma_{k}^{2}$ and $\omega_{h}^{2}$ variance elements characterizing the variancecovariance matrices of $\mu$ and $\eta$, respectively. Let $\theta$ be a vector of the $\theta_{k}$ elements; $\gamma$ be a vector of the $\gamma_{k}$ elements, $\sigma$ be a vector of parameters characterizing the variance-covariance matrix of $\mu$ (i.e., all the $\sigma_{k}^{2}$ elements); and $\omega$ be a vector of parameters characterizing the variance-covariance matrix of $\eta$ (i.e., all the $\omega_{h}^{2}$ elements).

The maximum likelihood inference approach is used to estimate the parameters of the MMDCEV model. To develop the likelihood function for parameter estimation, the probability of each sample individual's set of observed time investments is needed. Conditional on $\eta_{q}$ and $\mu_{q}$, the likelihood function for individual $q$ 's observed set of time investments is:

$$
\mathscr{L}_{q}(\theta, \gamma, \beta) \mid\left(\eta_{q}, \mu_{q}\right)=\prod_{t=1}^{T_{q}}\left[P\left(\boldsymbol{x}_{q t}^{*}, \theta, \gamma, \beta\right) \mid \eta_{q}, \mu_{q}\right] .
$$

The unconditional likelihood function for individual $q$ 's observed set of choices is: 


$$
\mathscr{L}_{q}(\theta, \gamma, \beta, \omega, \sigma)=\int_{\eta} \int_{\mu}\left[\mathscr{L}_{q}(\theta, \gamma, \beta) \mid(\eta, \mu)\right] d \boldsymbol{F}(\eta \mid \omega) d \boldsymbol{F}(\mu \mid \sigma) .
$$

The log-likelihood function is:

$$
\mathscr{L}(\theta, \gamma, \beta, \omega, \sigma)=\sum_{q} \ln \left[\mathscr{L}_{q}(\theta, \gamma, \beta, \omega, \sigma)\right]
$$

where $\boldsymbol{F}$ is the multivariate cumulative normal distribution. The reader will note that the dimensionality of the integration in the above expression depends on the number of elements in $\mu$ and $\eta$.

Simulation techniques are applied to approximate the multidimensional integral in Equation (7), and the resulting simulated log-likelihood function is maximized. Specifically, the scrambled Halton sequence (see Bhat, 2003) is used to draw realizations from the population normal distribution. In the current paper, the sensitivity of parameter estimates was tested with different numbers of scrambled Halton draws per individual, and results were found to be stable at about 400 draws, though we tested up to 550 draws to be sure that there was parameter stability over a reasonable spectrum of draws. In this analysis, we provide the results with 550 draws per individual.

\section{DESCRIPTIVE ANALYSIS OF MULTI-WEEK DATA}

Table 1 presents an overall profile of discretionary activity participation and duration for the sample of observations. If one were to consider the 852 weekly observations (recall $71 \times 12=$ 852), then one can determine the percent of weeks in which at least one activity episode of a certain type occurred. For example, at least one social activity was pursued in 64 percent of the 852 weeks covered by the sample (see the first numerical cell in Table 1). On the other hand, cultural and personal business activities were pursued in only about 35 percent of the weeks. Similar to social activities, leisure activities were pursued in more than 60 percent of the weeks covered by the sample. Average activity durations are computed both for the set of observations in which the activity occurred at least once (i.e., eliminating zero observations) and for the entire sample of 852 weekly observations. The column "Specific" refers to the average calculated over the non-zero observations, while the column "All" refers to the entire sample of 852 observations. It is found that average weekly time spent tends to be highest for social and leisure activities at about 8 hours per week (for the set of observations where the activity occurred) and 5 hours per week (across the entire sample). Overall, 93 percent of the week observations 
contained at least one of the $\mathrm{OH}$ discretionary activities, and the average time allocation per week is about 1100 minutes ( 18 hours) for all OH discretionary activities together. Recall that the "other" category is considered to be the "outside good" and is "consumed" by everybody.

Following this preliminary descriptive analysis of the sample, an analysis of variance (ANOVA) was performed to analyze and compare inter-individual variation in weekly activity time-use against intra-individual week-to-week variation. Two different measures of activity time use were used to analyze variance in activity time use patterns - the weekly activity participation and the weekly activity duration. The activity duration variance-analysis was performed both for the "Specific" sample and for the "All” sample identified in Table 1. The results of the ANOVA are reported in Table 2.

The results in Table 2 show that the total variation in terms of activity participation is about the same across the several discretionary activity types. The highest level of intraindividual (week-to-week) variation from an activity participation standpoint is for social and cultural activities, while the lowest level is for sports activities (presumably because of such activities being organized and routinized). From a weekly activity duration standpoint, social and leisure activities exhibit the highest level of inter-, intra-, and total variance, followed by the meals activity (for both the "Specific" and "All" samples). This is consistent with expectations, as one would indeed expect the highest level of variance in activity duration to be associated with the most discretionary-type activities. Overall, the differences in variance across activity categories are less pronounced when one considers activity participation rates relative to when one considers activity durations. In other words, it appears that activity participation (whether or not an activity is pursued) may be more stable or uniform both across individuals and within individuals; what varies more is the amount of time that is allocated to activity engagement both between individuals and within individuals.

Figure 1 presents the ANOVA results in a format that allows a clear analysis of the relative magnitudes of inter-individual and intra-individual (week-to-week) variance in activity participation and activity duration conditional on participation (i.e., "activity duration (specific)"). The dark bar shows the ratio of intra-individual variance to total variance, while the lighter bar shows the ratio of inter-individual variance to total variance. It is interesting to note that, for all activity purposes and both measures of time-use (except for cultural activities for activity duration "specific"), the intra-individual (or within-individual) variance proportion is 
greater than the inter-individual variance proportion. This suggests that even a week is not adequate when capturing time-use in disaggregate discretionary activities, and highlights the importance of collecting multi-week data; with a single-week data, one is missing a large proportion of the total variance in activity engagement patterns in the population. Intraindividual variance appears to be the largest for social activities for both measures of time-use. The results also show that while there is considerable variation in individual activity participation in cultural activities week-to-week, the individual-level variation in weekly activity duration in cultural activities given participation is the lowest. The highest level of interindividual variation in activity participation is observed in sports activity participation, indicating the higher level of variation between individuals when it comes to participating in sports. These results offer initial insights into what might be expected from the MMDCEV model results. For example, it is expected that the standard deviation term of the error component in the baseline preference corresponding to the sports activity category will be higher than that of other activity categories.

An important note is in order here in the context of the data set used to understand intraindividual and inter-individual variation in weekly activity participation behavior. The 71individual, 12-week data used for the analysis may appear to be relatively small in terms of the number of individuals, especially in extracting information about the inter-individual variation. To assess the influence of the number of individuals in the data on our results, we performed an analysis of variance (ANOVA) with different numbers of individuals. Specifically, we performed ANOVA analysis for: (1) 71 individuals, (2) 50 individuals, and (3) 35 individuals. A comparison of the ANOVA results indicated that reducing the number of individuals had little effect on the estimated ratio between the intra-individual variance and the inter-individual variance in weekly activity participation in any type of activity (the ANOVA results are available from the authors upon request). To be sure, we also performed further ANOVA analyses by reducing the number of weeks considered (for all 71 individuals in the data). This too did not have much impact on the ratios between intra- and inter-individual variances. Thus, we feel reasonably confident in the ability of the sample to support the rigorous modeling exercise undertaken. However, future efforts should consider collecting data from a higher number of individuals (say, 500 or more) over a multi-week period, so that more inter-individual variation in the independent variables is available to estimate independent variable effects. 


\section{MODEL ESTIMATION RESULTS}

This section discusses and compares the estimation results of the panel MMDCEV model and the cross-sectional MDCEV model. First, the baseline preference and satiation estimates are explained (Section 5.1), then the unobserved heterogeneity estimates (Section 5.2) are discussed, and finally the model performance measures (Section 5.3) are presented and discussed. The model performance measures include: (a) likelihood-based measures of goodness of fit (Section 5.3.1) and (b) marginal effects of exogenous variables (Section 5.3.2).

\subsection{Baseline Preference and Satiation Parameter Estimates}

The estimation results of the panel MMDCEV model and the cross-sectional MDCEV model are presented in the first six numeric columns and the last six numbered columns, respectively, of Table 3. In the results shown in Table 3, the "Other" activity category is the base alternative in the model specification. A '-' entry under a particular activity category for a particular variable implies that this variable is omitted from the utility specification. For each estimated parameter, the t-statistic is provided in parentheses below the parameter estimate.

The first row of parameters corresponds to the baseline preference constants that capture generic tendencies to participate in each $\mathrm{OH}$ discretionary activity purpose category. Since there are only dummy independent variables in the specification, the baseline preference constants reflect overall alternative preferences for the base population segment defined by the combination of the base categories across the dummy exogenous variables. All of the baseline preference constants for the out-of-home discretionary activities are negative in both the models, indicating the overall higher participation levels in the "Other" activity category (which is the base alternative in the model specification). This result is consistent with expectations because all of the individuals in the sample participate in this "other" activity category. Note that the baseline parameter estimate for the "cultural" activity type is substantially lower in the panel MMDCEV model that controls for unobserved individual heterogeneity relative to the crosssectional model that does not control for unobserved individual heterogeneity.

The next row of parameters corresponds to the translation parameters " $\gamma_{k}$ ". These parameters indicate the differences in the satiation effects (along with allowing for corner solutions or zero activity durations) among the different activity types, with a value closer to zero 
indicating a higher satiation effect (and a potentially lower activity duration). The higher values of $\gamma_{k}$ for social and cultural activities indicate lower satiation effects in those activities, when compared to other activities. Further, as expected, the highest satiation effect is associated with sports activity (this is consistent with the low weekly activity duration in sports activity in Table 1). The satiation effects in Table 3 are after controlling for observed variable effects.

The subsequent rows of parameters correspond to individual and household-level variable effects on baseline preferences. Among the individual-level variables, age is found to be a significant factor affecting out-of-home discretionary activity engagement in both the models. However, in the panel model, those in the age groups 16-35 years and 36-55 years show a higher propensity than those older than 55 years to undertake meal activities, and those in the 36-55 year age bracket show a higher propensity to engage in sport activities. This finding is consistent with expectations that people from younger (less than 55 years) age groups may be more inclined toward out-of-home activities (see, for example, Habib et al., 2008; and Meloni et al., 2007); especially for meal and sport activities. On the other hand, the cross-sectional model results with respect to age indicate that people in the 16-35 and 36-55 age groups are less inclined to invest time in leisure activities when compared to the older age-group (age > 55).

The next variable corresponds to those who are either married or in a cohabiting arrangement. The panel model estimates indicate that married individuals or those in a cohabiting arrangement are less likely to pursue cultural activities, possibly due to other household obligations and activities. However, the cross-sectional model results indicate that married or cohabiting individuals are less inclined toward meal and sport activities and more inclined toward leisure and personal business activities. It is interesting to note these differences across the panel and the cross-sectional models, specifically in the context of the unobserved individual-level inter-activity correlations considered by the panel model (more on this at the end of the next section).

The next, home-maker, variable appears only in the panel model, showing a negative influence on out-of-home meal activity participation and a positive influence on personal business activity participation. It is reasonable to expect that home-makers are less likely to eat out and that they spend significant amount of time in personal business activities.

The coefficients of the variable "high education (university graduate)" in the panel model indicate that higher educated individuals are less inclined to pursue social and sport activities. 
The cross-sectional model, on the other hand, indicates a positive association of high education with meal and cultural activities. Employed individuals, according to both the panel and the cross-sectional models, are more likely to pursue social activities, possibly due to the opportunities to interact with people at work place. However, this effect appears to be more pronounced with a high t-statistic in the cross-sectional model. In addition, the cross-sectional model estimates suggest that employed individuals are more likely to be associated with meal, sport, and cultural activities. The results from both the models appear to be consistent with the general findings from the existing literature (see, for example, Meloni et al., 2007 and Kapur and Bhat, 2007) that employed individuals are more inclined toward out-of-home discretionary activity participation. However, the results of the cross-sectional model, especially in the context of sport and cultural activities, do not appear to have a straight forward and intuitive explanation.

The variable "flexible work time", according to the panel model, is positively associated with meal activity participation. In the context of the "flexible work time" variable, the crosssectional model estimates indicate that flexible work time is associated with a higher inclination toward sport activity engagement. This result, though statistically significant, is difficult to explain. Among the income effects, those in the middle income range (2400-6000 per month in U.S. dollar equivalents) show a higher propensity than those in the low or high income categories to engage in sport activities for both panel and cross-sectional models. This result needs further investigation and verification from other weekly-level studies. The cross-sectional model shows additional positive impacts of medium-level income on cultural and personal business activities.

The presence of a dog (pet) is positively associated with the pursuit of leisure activities in both panel and cross-sectional models (see Bhat et al., 2005 and Brown and Rhodes, 2006 for a similar result). This is reasonable because those who own a dog are more likely to walk as part of their pet-walking activity (a large share of leisure activity episodes in the sample are in fact walking episodes). However, the cross-sectional model estimates provide clearly unintuitive results such as the negative association of the presence of a dog with meal and sport activity participation.

The next set of variables corresponds to household and residential location characteristics. Among these, the coefficients on "number of children" in both models indicate that the propensity to engage in meal and leisure activities decreases with the increase in the 
number of children. This result is reasonable because individuals from households with children may have a higher level of household and child obligations associated with the presence of children (see, for example, Kitamura 1984).

Among the residential location variables, the panel model estimates indicate, as expected (see, for example, Pinjari et al., 2008), that higher levels of accessibility to service establishments positively impacts engagement in out of home meal activities. The cross-sectional model also indicates a positive association of accessibility with meal activities. However, the negative effect of accessibility on sports activities in this model is not a very plausible result. Finally, the cross-sectional model shows several statistically significant effects of the "environment where individual grew up - big town" variable on activity preferences, while the panel model does not show any statistically significant effect of this variable.

In summary, both the panel and cross-sectional models provide reasonable and similar interpretations for several individual and household socio-demographic variables. However, the cross-sectional model provides a number of difficult-to-explain and/or counterintuitive results. Further, the cross-sectional model identifies a larger number of observed variable effects than those in the panel model. These differences are due to the difference in the way the unobserved factors are treated in the two models. In the panel model, as explained in Section 3, the unobserved factors are disentangled into intra-individual and inter-individual variations. Further, the inter-alternative correlations due to common individual and household level unobserved factors affecting the preferences of several activity types are captured in the panel model. On the other hand, the cross-sectional model ignores the week-to-week intra-individual variability as well as the inter-alternative correlations. The neglect of such unobserved individual factors, as indicated earlier, will lead to inconsistent behavioral relationships as is indicated in the different behavioral inferences from the cross-sectional and panel models. The following section discusses and analyzes the unobserved effects found from the panel model.

\subsection{Unobserved Heterogeneity Results}

As discussed in the section on modeling methodology, the model system used in this paper accommodates (a) Variations in baseline preference due to unobserved individual-specific factors, (b) Covariation in the baseline preference of different activity purposes generated by unobserved individual-specific factors, and (c) Variations in baseline preference due to 
unobserved intra-individual factors. In the next section, we discuss the first two elements listed above. We do not discuss the third component here because the unobserved intra-individual error terms are normalized with a variance of one in this paper. In the subsequent section, the explanatory variable effects, the unobserved inter-individual heterogeneity effects, and the unobserved intra-individual heterogeneity effects are brought together to provide an interpretation of the fraction of inter- and intra-individual variation in the baseline preference of each discretionary activity alternative.

\subsubsection{Unobserved Inter-Individual Heterogeneity and Covariance Among Baseline Preferences}

The unobserved pure variance inter-individual heterogeneity terms $\sigma_{k}^{2}$ (corresponding to the variance of the $\mu_{q}^{\prime} s_{k}$ terms in the modeling methodology section) are all highly significant from a statistical standpoint (see the last but one row of Table 3). This indicates substantial variation across individuals in the overall preference for each of the out-of-home discretionary activity type categories. In particular the highest value (with a high t-statistic) of the standard deviation of the sport activities indicates the presence of a wide variation (across individuals) in intrinsic preference for participation in sports. This result is consistent with the highest inter-personal variation in sports activity participation found in the ANOVA analysis (see Figure 1).

The standard deviation of the error terms that capture correlation in individual-specific unobserved factors $\omega_{h}^{2}$ (corresponding to the variance of $\eta_{q}^{\prime} w_{k}$ terms) affecting the utility equations are shown in the last row of Table 3 (several other identifiable error component specifications to generate covariance across the baseline preferences of alternatives were also attempted, but were not statistically significant). The results indicate that individuals having a higher (or lower) than normal propensity (i.e., the average propensity in the observationally identical peer group of individuals) to participate in social activities (due to unobserved individual-specific factors) are also likely to have a higher (or lower) than normal propensity to participate in meal activities. The same holds for the propensity to participate in sport and cultural activities, and in leisure and personal business activities. The significant error correlation between social and meals utilities may be due to the inherent tendency to be (or not to be) a social or outgoing person. Similarly, the significant error correlation between sports and cultural activity utilities may be attributed to the inherent interest in participating in and watching sports 
events (note that cultural activities includes sporting events). Finally, the significant error correlation between leisure and personal business activity utilities may be due to the inherent possibility and opportunity to easily link leisure activities (such as going for a walk or window shopping) together with personal business activities (running simple errands). Overall, the model estimation results and the interpretations that one can draw from the results are quite intuitively appealing and demonstrate the ability of the panel MMDCEV model to capture the range of observed and unobserved effects influencing multiple discretionary activity participation.

The discussion above indicates the presence of heterogeneity, but does not provide an intuitive sense of the magnitude of the different sources of unobserved heterogeneity and the effect of observed inter-individual heterogeneity (i.e., the effect of explanatory variables as captured in $\beta^{\prime} z_{q k}$; see the modeling methodology section earlier). The next section formulates an innovative way to translate the panel MMDCEV model estimates into more intuitive measures.

\subsubsection{Variance Components of Baseline Preferences}

The observed inter-individual heterogeneity effects, and the variances of the unobserved heterogeneity terms, provide important information regarding the fraction of variation in the baseline preference explained by observed variables and by unobserved factors. To see this, consider Equation (3) for the inside goods and take the logarithm of both sides of the equation to yield the following equation:

$$
\ln \psi_{q t k}=\left(\theta_{k}+\beta^{\prime} z_{q k}+\mu_{q}^{\prime} s_{k}+\eta_{q}^{\prime} w_{k}+\varepsilon_{q t k}\right)
$$

Then, the variance across weekly choice episodes of the (log) baseline preference for purpose $k$ can be partitioned as follows (using the notation already presented in the section on the modeling methodology):

$$
\operatorname{Var}\left[\ln \psi_{q t k}\right]=\operatorname{Var}\left(\beta^{\prime} z_{q k}\right)+\left[\left(\sigma_{k}^{2}+\sum_{h} w_{h k} \omega_{h}^{2}\right)+\frac{\pi^{2}}{6}\right],
$$

where $\operatorname{Var}\left(\beta^{\prime} z_{q k}\right)$ represents the variance due to observed inter-individual heterogeneity, $\left(\sigma_{k}^{2}+\sum_{h} w_{h k} \omega_{h}^{2}\right)$ represents unobserved inter-individual heterogeneity, and $\frac{\pi^{2}}{6}$ represents unobserved intra-individual heterogeneity (this is the variance of the $\varepsilon_{q t k}$ term). 
The percentage of variation in the logarithm of baseline preference explained by each of the different variance components can be computed from the estimates of $\beta$ and the estimated variance of the error components. These percentages are presented in Table 4 for the discretionary activity purposes. The percentage of variation captured by observed and unobserved factors is indicated first. Next, within unobserved heterogeneity, the percentage of variation captured by intra- and inter-individual heterogeneity is presented in italics. Thus, the number associated with inter-individual unobserved heterogeneity in Table 4 indicates the percentage of total unobserved heterogeneity captured by inter-individual heterogeneity. Several important observations may be drawn from this table. First, there are quite substantial differences in our ability to explain the baseline preference across activity purposes, as can be observed from the numbers in bold (first two rows) of Table 4. The best prediction ability is for meals and sports, and the poorest is for time-use in leisure, personal business and social activities. The former set of activity types is more well-defined, while the latter set has more ambiguity in what kinds of activities are included. This may be contributing to the result just identified. Second, there are also substantial variations across purposes in the percentage of total unobserved heterogeneity captured by inter-individual variation and intra-individual variation. The unobserved variation in the baseline preference across weeks of the same individual is higher than the unobserved variation in the baseline preference across individuals for all activity purposes except "sports". This implies that there is quite substantial variation in participation and time investments in the discretionary activity purposes of an individual from one week to the next. This is particularly so for the social activity purpose. Third, the magnitude of both interindividual and intra-individual unobserved heterogeneity is sizable for all activity purposes. This reinforces the need to collect multiweek data that can estimate and disentangle these two sources of unobserved heterogeneity, thus allowing the accurate and reliable estimation of explanatory variable effects.

Finally, a joint examination of the observed variable effects and unobserved effects provides some insights on the differences between the panel model and the cross-sectional model. Note from Table 3 that three pairs of activities (i.e., social and meal, sport and cultural, and leisure and personal business) are found to be associated with common unobserved factors (or correlation effects) in the panel model. Also note from the observed variable effects in the panel model that no observed variable has a statistically significant impact simultaneously on 
any of these pairs of activities. On the other hand, in the cross-sectional model, several observed variables show an impact on one or more of the above identified pairs of activities. For example, married or cohabiting individuals have a negative impact on social and meal activity pair, and a positive impact on the leisure and personal business activity pair. Similarly, the "employed" dummy variable has positive coefficients associated with the social and meal activity pair and the sport and cultural activity pair. Note from the discussion in the previous section that several of

these effects are difficult to explain and/or unintuitive. That is, some of the variable effects identified in the cross-sectional model are a result of the confounding effect of neglected individual-specific unobserved factors. The panel model "cleanses" the observed coefficient estimates by capturing such individual-specific unobserved factors through the correlations among the three pairs of activities identified above.

\subsection{Model Performance}

\subsubsection{Likelihood-based Measures of Fit}

The log-likelihood value for the cross-sectional MDCEV model at constants (i.e., with no observed socio-demographic variables and no error components in the baseline utility specification) is -20,747.82. Further, the log-likelihood value at convergence for the final “panel” MMDCEV model (with the error components) is -20,110.61, and that for the final crosssectional MDCEV model is -20,483.10. We also estimated another cross-sectional MDCEV model with exactly the same observed variables as in the panel MMDCEV model, whose loglikelihood value is $-20,507.47$ The likelihood ratio index between this cross-sectional model and the panel MMDCEV model for testing the presence of heterogeneity and alternative utility correlations due to individual-specific unobserved factors is 793.72, which is larger than the critical $\chi^{2}$ value with 9 degrees of freedom (corresponding to all of the error components in the panel MMDCEV model) at a level of confidence greater than 99.9\%. These results highlight the presence of significant individual-specific unobserved factors that impact activity participation and duration decisions (and the need to capture the "panel" effects and inter-alternative correlations). 


\subsubsection{Aggregate Marginal Effects}

Table 5 presents the aggregate marginal effects on discretionary activity time allocation. As can be observed from the table, the signs of the marginal effects of both the models are consistent with the corresponding model coefficients. The reader will note that the marginal effects indicate that each variable has some non-zero marginal effect on each discretionary activity, even if the variable impacts the baseline preference of only one activity type in Table 3. This is because a change in time allocation to one activity has the indirect effect of changing time allocations to other activities given the overall time-budget constraint. However, as expected, it is generally the case that the highest marginal impact of a variable is for the activity type whose preference it directly impacts in Table 3.

Table 5 indicates that the difference (between the two models) in model parameters has resulted in substantial differences in the magnitude of marginal effects. These differences highlight the extent of the differences from the two models. The cross-sectional model provides very different and inconsistent behavioral implications because it does not control for the effect of individual-level unobserved heterogeneity, as already discussed earlier. Thus, using the crosssectional model for forecasting time-use in response to changes in demographics or the built environment over time, or in response to policy scenarios, will, in general, provide incorrect results because the behavioral relationship embedded in the cross-sectional model is inappropriate.

\section{CONCLUSIONS}

It is increasingly realized in activity-travel behavior research that one needs to consider a longer period than a single day to capture the range of activity engagement patterns pursued by individuals. Many discretionary activities are undertaken only on an occasional basis and there may be significant day-to-day and week-to-week variability and tradeoffs associated with such activity engagement. While there have been some attempts at examining activity-travel behavior on a multi-day or weekly basis, to our knowledge, no previous study has attempted to quantify weekly-level inter-individual variability and week-to-week intra-individual variability in activity time-use patterns. Further, multi-period studies have rarely considered activity participation and durations for multiple activity categories simultaneously. To fill these gaps, this paper presents a 
detailed multi-week analysis and model of discretionary activity participation using a 12-week leisure activity-travel survey administered to a sample of 71 individuals in Zurich, Switzerland.

This paper makes key contributions on multiple fronts. First, the study contributes to an understanding of the determinants of weekly discretionary activity-travel behavior. Second, the study quantifies the weekly-level inter-individual and week-to-week intra-individual variability in activity participation and time-use in various discretionary activities. Third, the paper presents a panel version of the Mixed Multiple Discrete Continuous Extreme Value (MMDCEV) model that is capable of simultaneously accounting for repeated observations from the same individuals (panel), participation in multiple activities in a week, durations of activity engagement in various activity categories, and unobserved individual-specific factors affecting discretionary activity engagement including those common across pairs of activity category utilities. To our knowledge, this is the first formulation and application of a panel MMDCEV structure in the econometric literature.

The results of estimating the panel MMDCEV model system on the data set yielded intuitively meaningful interpretations. Comparison of the panel MMDCEV model estimates with the cross-sectional MDCEV model estimates highlighted the need to consider individual-specific unobserved heterogeneity effects in a panel model to capture appropriate behavioral relationships between weekly discretionary activity time-use and explanatory variables. In addition, the panel MMDCEV model allowed us to quantify and assess the relative magnitudes of within-individual week-to-week variation and between individual variation in the preference for discretionary activities. The analysis revealed that week-to-week intra-individual variation is greater than inter-individual variation in discretionary activity participation for virtually all activity categories, suggesting the importance of collecting and analyzing multi-period activity-travel data in the context of discretionary activity participation. The greatest inter-individual variance occurred in sports activity participation.

In summary, activity-travel behavior models that purport to capture discretionary activity participation using a single-day or even single-week travel behavior data set are likely to be missing key aspects of behavior and misrepresenting the true nature of engagement in such activities. Thus, consistent with previous literature on multi-period travel behavior analysis, this paper also points to the need to collect and analyze longitudinal data for multi-week durations for modeling discretionary activity participation. Careful attention needs to be paid to the design 
and administration of surveys that are capable of collecting such information over a longer period of time while minimizing respondent burden. In this context, serious consideration should be given to the more extensive use of emerging technologies (e.g. cell phone with integrated GPS capabilities) for collecting activity-travel information (see Stopher, 2008, Stopher et al., 2008, and Wolf et al., 2006).

\section{ACKNOWLEDGMENTS}

The authors acknowledge the helpful comments of four anonymous reviewers on an earlier version of the paper. The authors are also grateful to Lisa Macias for her help in typesetting and formatting this document. 


\section{REFERENCES}

Bhat CR (1999) An analysis of evening commute stop-making behavior using repeated choice observations from a multiday survey. Transportation Research Part B 33 (7): 495-510.

Bhat CR (2000) Incorporating observed and unobserved heterogeneity in urban work travel mode choice modeling. Transportation Science 34 (2): 228-238.

Bhat CR (2003) Simulation estimation of mixed discrete choice models using randomized and scrambled Halton sequences. Transportation Research Part B 37 (9): 837-855.

Bhat CR (2005) A multiple discrete-continuous extreme value model: formulation and application to discretionary time-use decisions Transportation Research Part B 39 (8): 679-707.

Bhat CR (2008) The Multiple Discrete-Continuous Extreme Value (MDCEV) Model: Role of utility function parameters, identification considerations, and model extensions. Transportation Research Part B 42 (3): 274-303.

Bhat CR, Frusti T, Zhao H, Schönfelder S, Axhausen, KW (2004) Intershopping duration: an analysis using multiweek data. Transportation Research Part B 38 (1): 39-60

Bhat CR, Lockwood A (2004) On distinguishing between physically active and physically passive episodes and between travel and activity episodes: an analysis of weekend recreational participation in the San Francisco bay area. Transportation Research Part A 38 (8): 573-592.

Bhat CR, Misra R, (1999) Discretionary activity time allocation of individuals between in-home and out-of-home and between weekdays and weekends. Transportation 26 (2): 193-209

Bhat CR, Srinivasan S, Axhausen KW (2005) An analysis of multiple inter-episode durations using a unifying multivariate hazard model. Transportation Research Part B 39 (9): 797823.

Brown SG, Rhodes RE (2006) Relationships among dog ownership and leisure-time walking in western Canadian adults. American Journal of Preventive Medicine 30 (2): 131-136.

Diggle PJ, Liang K-Y, Zeger SL (1994) Analysis of Longitudinal Data. Clarendon Press, Oxford.

Doherty ST, Miller EJ, Axhausen KW, Gärling T (2002) A conceptual model of the weekly household activity-travel scheduling process. In: Stern E, Salomon I, and Bovy P (eds) Travel Behaviour: Spatial Patterns, Congestion and Modelling, Edward Elgar Publishing, Cheltenham, UK, pp 233-264.

Goodwin PB (1981) The usefulness of travel budgets. Transportation Research Part A 15: 97106.

Habib KM, Miller EJ, Axhausen KW (2008) Weekly rhythm in joint time expenditure for all athome and out-of-home activities: application of Kuhn-Tucker demand system model using multiweek travel diary data. Transportation Research Record 2054: 64-73.

Hanson S, Hanson P (1980) Gender and urban activity patterns in Uppsala. Geographical Review 70 (3): 291-299.

Hanson S, Huff JO (1986) Classification issues in the analysis of complex travel behavior. Transportation 13: 271-293.

Hanson S, Huff JO (1988) Repetition and day-to-day variability in individual travel patterns: implications for classification. In: Golledge R, Timmermans H (eds) Behavioral Modelling in Geography and Planning, Croom Helm, New York.

Hirsh M, Prashker JN, Ben-Akiva M (1986) Dynamic model of weekly activity pattern. Transportation Science 20 (1): 24-36. 
Huff JO, Hanson S (1986) Repetition and variability in urban travel. Geographical Analysis 18 (2): 97-113.

Huff JO, Hanson S (1990) Measurement of habitual behavior: examining systematic variability in repetitive travel. In: Jones P (ed) Developments in dynamic and activity-based approaches to travel analysis, Gower Publishing Co., Aldershot, England, pp 229-249.

Jones P, Clarke M (1988) The significance and measurement of variability in travel behaviour. Transportation 15: 65-87.

Juster FT, Ono H, Stafford FP (2004) Changing times of american youth: 1981-2003. Institute for Social Research, University of Michigan, Ann Arbor, Michigan

Kapur A, Bhat CR (2007) On modeling adults' daily time use by activity purpose and accompaniment arrangement. Transportation Research Record 2021:18-27.

Kitamura R (1984) A model of daily time allocation to discretionary out-of-home activities and trips. Transportation Research Part B 18 (3): 255-266.

Kitamura R (1988) An analysis of weekly activity patterns and travel expenditure. In: Golledge R, Timmermanns H (eds) Behavioural Modelling in Geography and Planning, Croom Helm, London, pp 399-423.

Koppelman FS, Pas EI (1984) Estimation of disaggregate regression models of person trip generation with multiday data. In: Volmuller J, Hamerslag R (eds) Proceedings of the Ninth International Symposium on Transportation and Traffic Theory, VNU Science Press, Utrecht, The Netherlands, pp 513-529.

Kraan M (1996) Time to travel? a model for the allocation of time and money. Unpublished PhD dissertation, Department of Civil Engineering, University of Twente, The Netherlands.

Kunert U (1994) Weekly mobility of life cycle groups. Transportation 21 (3): 271-288.

Meloni I, Spissu E, Bez M (2007) A model of the dynamic process of time allocation to discretionary activities. Transportation Science 41 (1): 15-28.

Mohammadian A, Doherty S (2005) Mixed logit model of activity-scheduling time horizon incorporating spatial-temporal flexibility variables. Transportation Research Record 1926: 33-40.

Mohammadian A, Doherty S (2006) Modeling activity scheduling time horizon: duration of time between planning and execution of pre-planned activities. Transportation Research Part A 40: 475-490.

Muthyalagari GR, Parashar A, Pendyala RM (2001) Measuring day-to-day variability in travel characteristics using gps data. CD-ROM Proceedings of the 80th Annual Meeting of the Transportation Research Board, TRB, National Research Council, Washington, D.C.

Newman C (2002) Gender, time use, and change: impacts of agricultural export employment in Ecuador. The World Bank Economic Review 16 (3): 375-396.

Pas EI (1983) A flexible and integrated methodology for analytical classification of daily travelactivity behavior. Transportation Science 17: 405-429.

Pas EI (1987) Intrapersonal variability and model goodness-of-fit. Transportation Research Part A 21 (6): 431-438.

Pas EI (1988) Weekly travel-activity patterns. Transportation 15: 89-109.

Pas EI, Sundar S (1995) Intrapersonal variability in daily urban travel behavior: some additional evidence. Transportation 22: 135-150.

Pendyala RM, Kitamura R, Kikuchi A, Yamamoto T, Fujii S (2005) Florida activity mobility simulator. Transportation Research Record 1921: 123-130. 
Pendyala RM, Pas EI (1997) Summary of workshop two: models of activity engagement and travel behavior. In: Texas Transportation Institute (ed) Activity-Based Travel Forecasting Conference, June 2-5, 1996: Summary, Recommendations, and Compendium of Papers, Report DOT-T-97-17, Travel Model Improvement Program, U.S. Department of Transportation, Washington, D.C., pp 183-192.

Pinjari AR, Bhat CR, Hensher DA (2008) Residential self-selection effects in an activity timeuse behavior model. Technical paper, Department of Civil, Architectural \& Environmental Engineering, The University of Texas at Austin.

Schlich R (2004) 12 weeks of leisure travel survey. Travel survey meta data series, ETH.

Stauffacher M, Schlich R, Axhausen KW, Scholz R (2005) The diversity of travel behaviour: motives and social interactions in leisure time activities. Working papers, Transportation and Spatial Planning, IVT, ETH Zürich, Zürich.

Stopher PR (2008) Collecting and Processing Data from Mobile Technologies. Resource paper for Workshop B4: The Collection and Processing of Survey Data using Mobile Technologies, $8^{\text {th }}$ International Conference on Survey Methods in Transport, Annecy, France.

Stopher PR, FitzGerald C, Zhang J (2008) Search for a global positioning system device to measure person travel. Transportation Research Part C 16(3): 350-369.

Wolf J, Bonsall P, Oliveira M, Leary L, Lee M (2006). “Review of relevant technologies” Report on work package 1 of Research Project UG599 (Review of the Potential Role of 'New Technologies' in the National Travel Survey), Department for Transport, London. http://www.dft.gov.uk/pgr/statistics/datatablespublications/personal/methodology/ntsrepo rts/ntsreviewtechnologies.pdf 


\section{List of Figures:}

Figure 1. Relative magnitudes of intra- and inter-individual variance

\section{List of Tables:}

Table 1. Weekly Time Use Profiles

Table 2. Results of Analysis of Variance

Table 3. Model Estimation Results

Table 4. Percentage of Variation in the Logarithm of Baseline Preference Explained by Observed and Unobserved Factors

Table 5: Marginal effects of Panel MMDCEV and Cross-sectional MDCEV (\% of variation) 


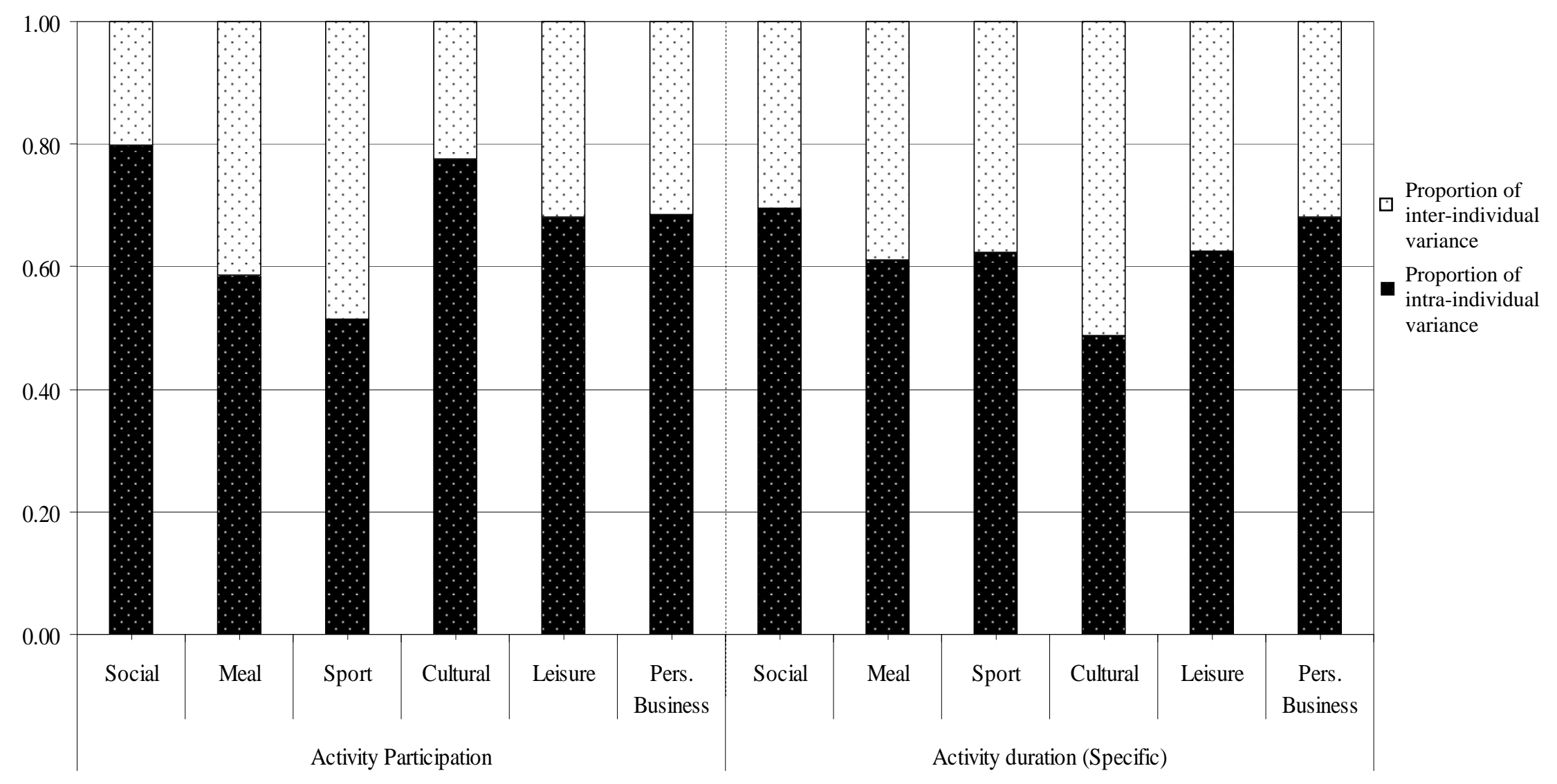

Figure 1. Relative magnitudes of intra- and inter-individual variance 
Table 1. Weekly Time Use Profiles

\begin{tabular}{|l|c|cc|}
\hline \multirow{2}{*}{ ACTIVITY TYPE } & \multirow{2}{*}{ PARTICIPATION } & \multicolumn{2}{|c|}{ ACTIVITY DURATION [min] } \\
\cline { 3 - 4 } & & Specific & All \\
\hline Social & $64.1 \%$ & 473.6 & 302.9 \\
Meal & $47.7 \%$ & 333.5 & 158.9 \\
Sport & $45.7 \%$ & 259.5 & 118.5 \\
Cultural & $35.3 \%$ & 324.4 & 114.6 \\
Leisure & $62.0 \%$ & 477.8 & 295.6 \\
Personal Business & $34.0 \%$ & 280.6 & 95.5 \\
\hline Overall & $92.7 \%$ & 1171.2 & 1086.0 \\
\hline Other & $100.0 \%$ & 4219.3 & 4219.3 \\
\hline
\end{tabular}

Table 2. Results of Analysis of Variance

\begin{tabular}{|c|c|c|c|c|c|c|c|}
\hline \multirow{2}{*}{\multicolumn{2}{|c|}{ ACTIVITY TYPE }} & \multicolumn{3}{|c|}{ ACTIVITY PARTICIPATION } & \multicolumn{3}{|c|}{ ACTIVITY DURATION } \\
\hline & & Inter & Intra & Total & Inter & Intra & Total \\
\hline \multirow{6}{*}{$\bar{\varangle}$} & Social & 0.05 & 0.18 & 0.23 & 48509.0 & 110284.7 & 158793.7 \\
\hline & Meal & 0.10 & 0.15 & 0.25 & 37558.9 & 39254.5 & 76813.4 \\
\hline & Sport & 0.12 & 0.13 & 0.25 & 15270.7 & 25705.9 & 40976.6 \\
\hline & Cultural & 0.05 & 0.18 & 0.23 & 11584.8 & 34979.5 & 46564.3 \\
\hline & Leisure & 0.08 & 0.16 & 0.24 & 102026.2 & 125790.9 & 227817.1 \\
\hline & Personal Business & 0.07 & 0.15 & 0.22 & 12751.4 & 28266.1 & 41017.5 \\
\hline \multirow{6}{*}{ 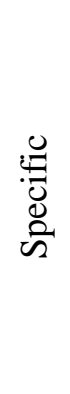 } & Social & - & - & - & 51035.3 & 116415.8 & 167451.0 \\
\hline & Meal & - & - & - & 39976.9 & 63069.7 & 103046.7 \\
\hline & Sport & - & - & - & 19997.2 & 33181.7 & 53178.9 \\
\hline & Cultural & - & - & - & 32707.1 & 31095.4 & 63802.5 \\
\hline & Leisure & - & - & - & 105603.2 & 175713.5 & 281316.7 \\
\hline & Personal Business & - & - & - & 21905.4 & 46752.4 & 68657.9 \\
\hline
\end{tabular}


Table 3. Model Estimation Results (t-statistics)

\begin{tabular}{|c|c|c|c|c|c|c|c|c|c|c|c|c|}
\hline \multirow[b]{2}{*}{ VARIABLE } & \multicolumn{6}{|c|}{ PANEL MMDCEV } & \multicolumn{6}{|c|}{ CROSS-SECTIONAL MDCEV } \\
\hline & Social & Meal & Sport & Cultural & Leisure & $\begin{array}{l}\text { Personal } \\
\text { Business } \\
\end{array}$ & Social & Meal & Sport & Cultural & Leisure & \begin{tabular}{|l|} 
Personal \\
Business \\
\end{tabular} \\
\hline Baseline preference constants $\left(\theta_{k}\right)$ & $\begin{array}{c}-8.116 \\
(-42.82)\end{array}$ & $\begin{array}{c}-9.950 \\
(-33.71)\end{array}$ & $\begin{array}{c}-9.539 \\
(-24.95)\end{array}$ & $\begin{array}{c}-8.201 \\
(-45.32)\end{array}$ & $\begin{array}{c}-7.750 \\
(-59.20)\end{array}$ & $\begin{array}{c}-9.380 \\
(-61.81)\end{array}$ & $\begin{array}{c}-8.382 \\
(-71.64)\end{array}$ & $\begin{array}{c}-9.30 \\
(-41.37)\end{array}$ & $\begin{array}{c}-8.937 \\
(-37.18) \\
\end{array}$ & \begin{tabular}{c|}
-9.512 \\
$(-64.33)$ \\
\end{tabular} & $\begin{array}{c}-8.055 \\
(-50.92)\end{array}$ & $\begin{array}{c}-9.65 \\
(-45.36)\end{array}$ \\
\hline Translation Parameters $\left(\gamma_{k}\right)$ & $\begin{array}{c}149.770 \\
(12.64)\end{array}$ & $\begin{array}{l}89.032 \\
(10.76)\end{array}$ & $\begin{array}{c}68.347 \\
(10.46)\end{array}$ & $\begin{array}{c}163.188 \\
(10.50)\end{array}$ & $\begin{array}{c}101.281 \\
(11.51)\end{array}$ & $\begin{array}{c}104.324 \\
(9.86)\end{array}$ & $\begin{array}{c}183.332 \\
(8.52)\end{array}$ & $\begin{array}{c}124.002 \\
(6.92)\end{array}$ & $\begin{array}{c}111.152 \\
(6.99)\end{array}$ & $\begin{array}{c}198.502 \\
(5.24)\end{array}$ & $\begin{array}{c}141.274 \\
(8.87)\end{array}$ & $\begin{array}{c}144.952 \\
(6.340)\end{array}$ \\
\hline \multicolumn{13}{|l|}{ Individual Characteristics } \\
\hline Age $16-35$ & - & $\begin{array}{l}1.715 \\
(6.30)\end{array}$ & - & - & - & - & - & - & - & - & $\begin{array}{l}-0.5 .25 \\
(-3.68)\end{array}$ & - \\
\hline Age $36-55$ & - & $\begin{array}{l}1.510 \\
(5.27)\end{array}$ & $\begin{array}{c}1.186 \\
(4.280)\end{array}$ & - & - & - & - & - & - & - & $\begin{array}{l}-0.323 \\
(-2.21)\end{array}$ & - \\
\hline Married or cohabiting & - & - & - & $\begin{array}{l}-1.127 \\
(-5.38)\end{array}$ & - & - & - & $\begin{array}{l}-0.602 \\
(-4.25)\end{array}$ & $\begin{array}{l}-0.456 \\
(-2.71)\end{array}$ & - & $\begin{array}{l}0.408 \\
(2.82)\end{array}$ & $\begin{array}{l}0.594 \\
(2.96)\end{array}$ \\
\hline Homemaker & - & $\begin{array}{l}-0.616 \\
(-1.53)\end{array}$ & - & - & - & $\begin{array}{l}0.732 \\
(3.16)\end{array}$ & - & - & - & - & - & - \\
\hline High education (university graduate) & $\begin{array}{l}-0.747 \\
(-3.48)\end{array}$ & - & $\begin{array}{l}-1.028 \\
(-3.11)\end{array}$ & - & - & - & - & $\begin{array}{l}0.988 \\
(5.92)\end{array}$ & - & $\begin{array}{l}0.496 \\
(2.96)\end{array}$ & - & - \\
\hline Employed & $\begin{array}{l}0.408 \\
(1.92)\end{array}$ & - & - & - & - & - & $\begin{array}{l}0.663 \\
(5.43)\end{array}$ & $\begin{array}{l}1.315 \\
(8.13)\end{array}$ & $\begin{array}{l}0.440 \\
(2.55)\end{array}$ & $\begin{array}{l}0.611 \\
(3.91)\end{array}$ & - & - \\
\hline Flexible work time & - & $\begin{array}{l}0.372 \\
(1.19)\end{array}$ & - & - & - & - & - & - & $\begin{array}{c}0.661 \\
(4.291)\end{array}$ & - & - & - \\
\hline Monthly individual income $\$ 2400$ - \$6000 & - & - & $\begin{array}{l}1.563 \\
(4.36)\end{array}$ & - & - & - & - & - & $\begin{array}{l}0.810 \\
(5.88)\end{array}$ & $\begin{array}{l}0.303 \\
(2.20)\end{array}$ & - & $\begin{array}{l}0.297 \\
(2.13)\end{array}$ \\
\hline Have a dog & - & - & - & - & $\begin{array}{l}0.362 \\
(1.60)\end{array}$ & - & - & $\begin{array}{l}-0.807 \\
(-3.51)\end{array}$ & $\begin{array}{l}-0.445 \\
(-2.12)\end{array}$ & - & $\begin{array}{l}0.681 \\
(3.43)\end{array}$ & - \\
\hline \multicolumn{13}{|l|}{$\begin{array}{l}\text { Household and Residential Location } \\
\text { Characteristics }\end{array}$} \\
\hline Number of children & - & $\begin{array}{l}-0.640 \\
(-2.76)\end{array}$ & - & - & $\begin{array}{l}-0.461 \\
(-3.59)\end{array}$ & - & - & $\begin{array}{l}-0.212 \\
(-2.078)\end{array}$ & - & - & $\begin{array}{l}-0.193 \\
(-2.21)\end{array}$ & - \\
\hline $\begin{array}{l}\text { More than } 4 \text { services (bus stop, school, } \\
\text { doctor, bank, office, market) within } 10 \\
\text { minutes from home }\end{array}$ & - & $\begin{array}{l}0.717 \\
(3.07)\end{array}$ & - & - & - & - & - & $\begin{array}{l}0.5461 \\
(3.40)\end{array}$ & $\begin{array}{l}-0.431 \\
(-3.69)\end{array}$ & - & - & - \\
\hline $\begin{array}{l}\text { Environment where person grew up } \\
\text { Big town }\end{array}$ & - & - & - & - & - & - & $\begin{array}{l}-0.242 \\
(-2.34) \\
\end{array}$ & - & $\begin{array}{l}0.368 \\
(3.01) \\
\end{array}$ & $\begin{array}{l}-0.391 \\
(-2.84) \\
\end{array}$ & - & - \\
\hline
\end{tabular}


(continued)Table 3. Model Estimation Results (t-statistic)

\begin{tabular}{|c|c|c|c|c|c|c|c|c|c|c|c|c|}
\hline \multirow{2}{*}{ VARIABLE } & \multicolumn{6}{|c|}{ PANEL MMDCEV } & \multicolumn{6}{|c|}{ CROSS-SECTIONAL MDCEV } \\
\hline & Social & Meal & Sport & Cultural & Leisure & $\begin{array}{l}\text { Personal } \\
\text { Business }\end{array}$ & Social & Meal & Sport & Cultural & Leisure & \begin{tabular}{|l} 
Personal \\
Business
\end{tabular} \\
\hline \begin{tabular}{|l} 
St. dev. of error component capturing \\
unobserved pure variance inter- \\
individual heterogeneity $\left(\sigma_{k}^{2}\right)$ in \\
baseline preference
\end{tabular} & $\begin{array}{l}0.390 \\
(4.48)\end{array}$ & $\begin{array}{l}0.949 \\
(7.03)\end{array}$ & $\begin{array}{l}1.685 \\
(8.48)\end{array}$ & $\begin{array}{l}0.416 \\
(2.73)\end{array}$ & $\begin{array}{l}0.792 \\
(7.59)\end{array}$ & $\begin{array}{l}0.793 \\
(6.50)\end{array}$ & & & & & & \\
\hline $\begin{array}{l}\text { St. dev. of error components for correlatio } \\
\omega_{h}^{2} \text { between } \\
\text { utilities of Social and Meal activities }\end{array}$ & \multicolumn{6}{|c|}{$\begin{array}{l}0.487 \\
(6.38)\end{array}$} & & & & & & \\
\hline utilities of Sport and Cultural activities & \multicolumn{6}{|c|}{$\begin{array}{l}0.907 \\
(6.38)\end{array}$} & & & & & & \\
\hline $\begin{array}{l}\text { utilities of Leisure and Personal business } \\
\text { activities }\end{array}$ & \multicolumn{6}{|c|}{$\begin{array}{l}0.640 \\
(4.91)\end{array}$} & & & & & & \\
\hline Log-likelihood & \multicolumn{6}{|c|}{$-20,110.608$} & \multicolumn{6}{|c|}{$-20,483.102$} \\
\hline
\end{tabular}


Table 4. Percentage of Variation in the Logarithm of Baseline Preference Explained by Observed and Unobserved Factors

\begin{tabular}{|c|c|c|c|c|c|c|}
\hline \multirow{2}{*}{ HETEROGENEITY SOURCE } & \multicolumn{6}{|c|}{$\begin{array}{l}\text { Percentage of variation in the logarithm of baseline preference in each activity purpose, } \\
\text { explained by each heterogeneity source }\end{array}$} \\
\hline & SOCIAL & MEAL & SPORT & CULTURAL & LEISURE & $\begin{array}{l}\text { PERSONAL } \\
\text { BUSINESS } \\
\end{array}$ \\
\hline Observed heterogeneity & 4.77 & 24.91 & 15.66 & 7.17 & 5.02 & 3.82 \\
\hline Unobserved heterogeneity & 95.23 & 75.09 & 84.34 & 92.83 & 94.98 & 96.18 \\
\hline Inter-individual & 19.12 & 40.87 & 69.00 & 37.69 & 38.66 & 38.70 \\
\hline Intra-individual & 80.88 & 59.13 & 31.00 & 62.31 & 61.34 & 61.30 \\
\hline
\end{tabular}


Table 5. Marginal effects of Panel MMDCEV and Cross-sectional MDCEV (\% of variation)

\begin{tabular}{|c|c|c|c|c|c|c|c|c|c|c|c|c|}
\hline & \multicolumn{6}{|c|}{ PANEL MMDCEV } & \multicolumn{6}{|c|}{ CROSS-SECTIONAL MDCEV } \\
\hline & Social & Meal & Sport & Cultural & Leisure & $\begin{array}{l}\text { Personal } \\
\text { Business }\end{array}$ & Social & Meal & Sport & Cultural & Leisure & $\begin{array}{l}\text { Personal } \\
\text { Business }\end{array}$ \\
\hline Individual Characteristics & & & & & & & & & & & & \\
\hline Age $16-35$ & -4.50 & 80.66 & -5.88 & -5.34 & -6.75 & -8.76 & 3.05 & 3.66 & 2.86 & 2.71 & -56.68 & 5.10 \\
\hline Age $36-55$ & -9.49 & 72.55 & 59.63 & -9.85 & -8.84 & -10.11 & 2.63 & 1.88 & 2.37 & 2.73 & -28.75 & 2.54 \\
\hline Married or cohabiting & 5.16 & 4.49 & 5.17 & -169.68 & 5.15 & 7.37 & 0.70 & -69.20 & -49.98 & 0.19 & 30.68 & 43.89 \\
\hline Home-maker & -1.47 & -82.84 & -0.85 & -3.62 & -1.80 & 48.68 & - & - & - & - & - & - \\
\hline High education (university graduate) & -74.50 & 9.22 & -129.61 & 10.74 & 7.23 & 8.50 & -9.23 & 55.29 & -9.91 & 30.55 & -10.35 & -11.19 \\
\hline Employed & 29.54 & -2.92 & -3.08 & -3.03 & -2.98 & -2.94 & 36.87 & 65.95 & 22.15 & 33.05 & -13.55 & -18.23 \\
\hline Flexible work time & -1.56 & 28.32 & -1.61 & -2.01 & -1.38 & -1.35 & -2.74 & -3.30 & 45.71 & -3.04 & -2.21 & -3.60 \\
\hline $\begin{array}{l}\text { Monthly individual income } \$ 2400 \text { - } \\
\$ 6000\end{array}$ & -6.14 & -6.51 & 74.62 & -7.53 & -5.32 & -8.92 & -6.26 & -6.84 & 49.70 & 19.29 & -5.17 & 18.99 \\
\hline Have a dog & -2.27 & -3.31 & -4.21 & -5.13 & 23.43 & -4.63 & -3.12 & -96.97 & -75.72 & -5.62 & 42.67 & -10.46 \\
\hline \multicolumn{13}{|l|}{$\begin{array}{l}\text { Household and Residential } \\
\text { Location Characteristics }\end{array}$} \\
\hline Number of children & 4.42 & -42.35 & 4.90 & 4.51 & -31.39 & 5.88 & 33.38 & -57.15 & 25.67 & 10.73 & -43.40 & -1.06 \\
\hline $\begin{array}{l}\text { More than } 4 \text { services (bus stop, school, } \\
\text { doctor, bank, office, market) } \\
\text { within } 10 \text { minutes from home }\end{array}$ & -1.92 & 47.60 & -2.73 & -2.22 & -2.38 & -2.25 & -0.06 & 34.11 & -49.98 & 0.36 & -0.15 & -0.31 \\
\hline $\begin{array}{l}\text { Environment where person grew up } \\
\text { Big town }\end{array}$ & - & - & - & - & - & - & -22.16 & 1.00 & 30.77 & -46.20 & 2.07 & 1.57 \\
\hline
\end{tabular}

